\title{
Machado River, Brazil - a newly recognised ultradeep diamond occurrence
}

\author{
G.P. Bulanova ${ }^{1}$, C.B. Smith ${ }^{2}$, S.C. Kohn ${ }^{1}$, M.J. Walter ${ }^{1}$, L. Gobbo ${ }^{3}$, S. Kearns ${ }^{1}$ \\ ${ }^{1}$ University of Bristol, UK; \\ ${ }^{2}$ Rio Tinto Mining and Exploration Ltd., London, UK; \\ ${ }^{3}$ Rio Tinto Desenvolvimentos Minerais Ltda., Brasilia, Brazil.
}

Machado River alluvial diamonds are located in Rondonia, Brazil, downstream from the diamondiferous Pimenta Bueno and Carolina Kimberlites (Fig.1). The nearby Araras kimberlites are barren. The occurrence lies within the 1.55-1.8 Ga Rio Negra-Juruena Mobile Belt on the southern margin of the Amazonian Craton, some $200 \mathrm{~km} \mathrm{~W}$ of the Juina ultradeep diamond field.

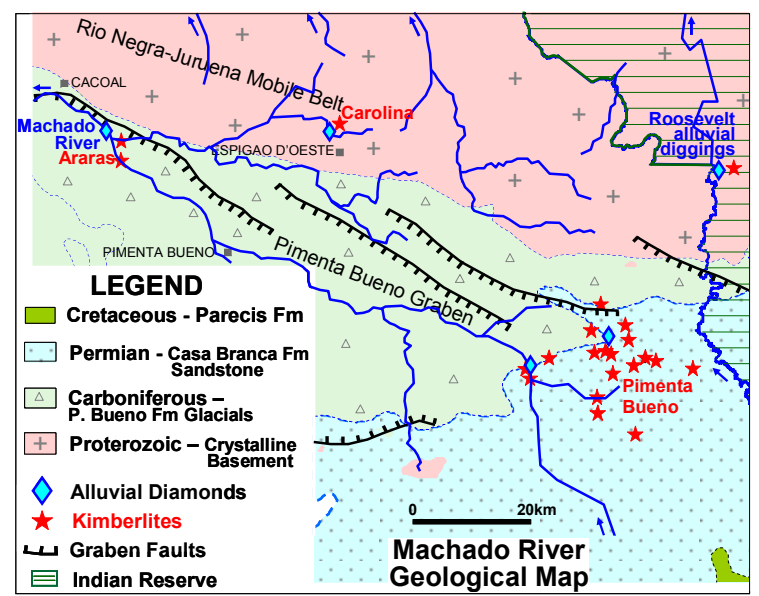

Fig 1. Geological map of Machado River territory.

$70 \%$ of Machado stones show abrasion features such as rhombic cracks and percussion marks (Fig. 2). Green and brown radiation spots are common, indicating recycling from palaeocollectors. But $30 \%$ of diamonds represented by white octahedrons, show little resorption and no signs of transportation wear. These differences clearly suggest more than one primary source for Machado River stones.

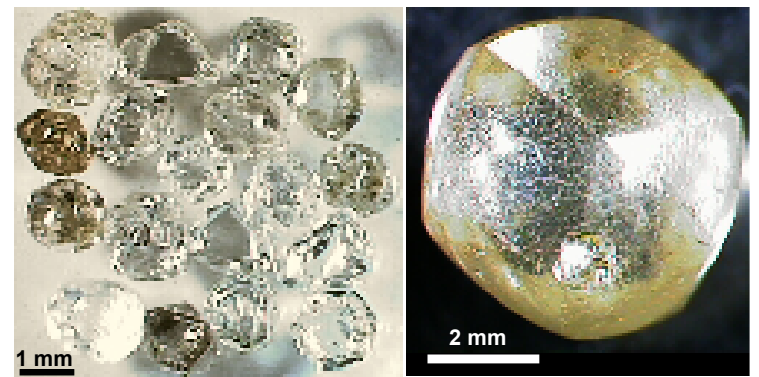

Fig 2. Morphology of Machado River diamonds.

25 stones $2-3 \mathrm{~mm}$ in size with mineral inclusions were selected from Rio Tinto's Machado River collection for study. The aim was to identify the diamond paragenesis and its correlation with the external morphology of the stones, and to establish a genetic link with diamondiferous kimberlites of the area.

The work carried out included: external morphology study; diamond polishing to expose inclusions and to produce central plates for internal structure study by $\mathrm{ABR}$ and $\mathrm{CL}$ imaging; $\mathrm{N}$ content and aggregation investigation by FTIR with data processing as described in Taran et al (2006); chemical analysis of inclusions using SEM, EMP, SIMS; and in-situ C isotope investigation by SIMS in core-rim traverses of the polished crystals. As a result, three genetic groups of the diamonds were identified: ultradeep (UD), eclogitic (E) and peridotitic (P).

\section{External and internal morphology}

The external morphology of the UD, E and P diamonds is similar. Dodecahedral diamond shapes predominate. Some $70 \%$ of stones have abrasion features, but other crystals are fresh octahedrons without mechanical wear.

Internal structure of the diamond populations is different. UD stones have nil or very weak PL, weak $\mathrm{CL}$ and are homogeneous, stressed and plastically deformed. Many diamonds are broken and even represented by fragments; the stones are resorbed, etched and have many internal cracks (Fig. 3).
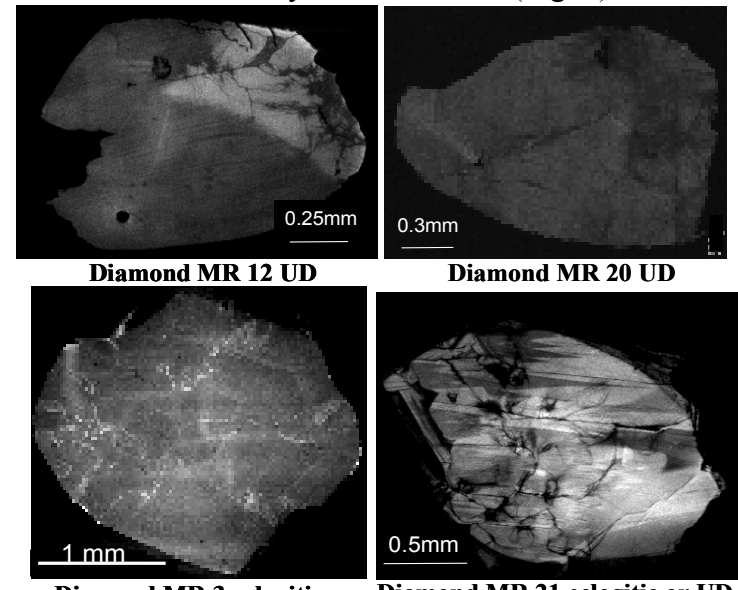

Diamond MR 20 UD

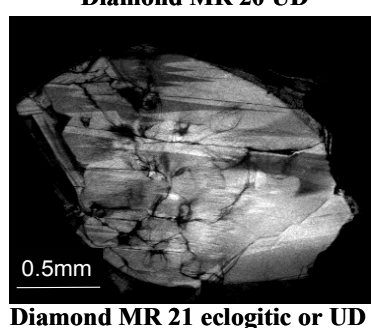

Diamond MR 3 eclogitic

Diamond MR 21 eclogitic or UD Fig. 3. CL images of internal structure of some UD and eclogitic Machado River diamonds. 
Eclogitic crystals have similar properties to ultradeep diamonds (Fig 3) or more rarely have bright PL and octahedral zonation in CL and ABR imageries (Fig. 4).

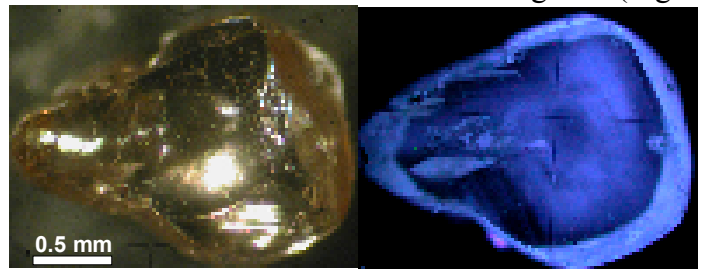

Fig. 4. E diamond MR 17 \& PL image of the plate.

Peridotitic diamonds have bright blue PL and octahedral zonation in CL imageries (Fig. 5).

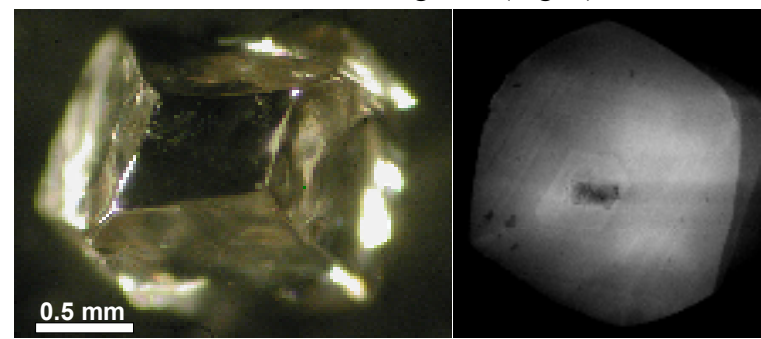

Fig. 5. Peridotitic diamond MR 14 and CL image of the diamond central plate.

\section{Nitrogen content and aggregation}

In agreement with internal structure, the three genetic diamond groups have different physical properties. UD stones are nitrogen free type II diamonds; only one crystal has low $\mathrm{N}$ and is highly aggregated $(96 \%$ of $1 \mathrm{aB})$. E diamonds contain $39-860 \mathrm{ppm}$ of nitrogen and $\mathrm{P}$ crystals have higher $\mathrm{N}$ concentration, 200 - 1500 ppm. Both $\mathrm{E}$ and $\mathrm{P}$ diamonds form three groups - low aggregated (4 - 7\% of $1 \mathrm{aB})$, medium aggregated (30$50 \%$ of $1 \mathrm{aB})$ and highly aggregated $(87-95 \%$ of $1 \mathrm{aB})$. Some E stones similar to the UD ones are type II.

G10 garnets indicative of depleted lithospheric mantle occur in local kimberlites (Teixeira et al., 2001). Such depleted mantle world-wide is often Archean in age. From this a minimum $2.4 \mathrm{Ga}$ diamond residence in the mantle could be postulated, assuming Mesozoic kimberlite emplacement. Applying this mantle residence time to time-temperature relationships for $\mathrm{N}$ aggregation, the $\mathrm{E}$ and $\mathrm{P}$ diamonds form three groups of high $\left(1200-1275^{\circ} \mathrm{C}\right)$, medium $\left(1150-1170^{\circ} \mathrm{C}\right)$ and low $\left(1000-1100^{\circ} \mathrm{C}\right)$ temperatures of formation. The lower temperature results would satisfy origin in lithospheric mantle. In contrast those UD diamonds containing nitrogen give very high temperatures $>1300^{\circ} \mathrm{C}$ suggestive of sub-lithospheric growth. The UD and high temperature eclogitic stones could grow from carbon in oceanic crust subducted during formation of the 1.55-1.8 Ga Rio Negra-Juruena Mobile Belt, resulting in much shorter mantle residence time which requires even higher formation temperatures to account for the $\mathrm{N}$ aggregation.

The $\mathrm{P}$ and $\mathrm{E}$ crystals show decreasing $\mathrm{N}$ content and aggregation from core to rim, as is normally found. One Machado stone shows very rough zonation with a core of high $\mathrm{N}$, laB-type changing into a wide rim zone of $\mathrm{N}$-free diamond type II.

\section{Mineral inclusions}

Ultradeep paragenesis comprises $\mathrm{MgSi}-$ and $\mathrm{Ca}-\mathrm{Si}$ perovskites, $\mathrm{Mg}$ ferropericlase, majorite and low-Ni sulphides (Table 1).

Table 1. Paragenesis of Machado River diamonds

\begin{tabular}{|c|c|c|c|}
\hline PARAGENESIS & MINERALS & TOTAL & $\%$ \\
\hline $\begin{array}{c}\text { Upper Mantle } \\
\text { Peridotitic }\end{array}$ & $\begin{array}{l}\mathrm{Ol} \\
\mathrm{Ol}+\mathrm{Opx} \\
\mathrm{Pn}\end{array}$ & $\begin{array}{l}3 \\
1 \\
1 \\
\end{array}$ & 25 \\
\hline $\begin{array}{l}\text { Upper Mantle } \\
\text { Eclogitic }\end{array}$ & $\begin{array}{l}\mathrm{Po} \pm \mathrm{Fe}-\mathrm{Al}-\mathrm{Si} \text {-phase } \\
\mathrm{SiO}_{2} \\
\mathrm{Cpx} \\
\mathrm{K}-\mathrm{Fsp}+\mathrm{Ap}\end{array}$ & $\begin{array}{l}4 \\
2 \\
1 \\
1\end{array}$ & 40 \\
\hline $\begin{array}{l}\text { Ultra Deep } \\
\text { Lower Mantle }\end{array}$ & $\begin{array}{l}\text { Opx (former Prv) } \pm \text { Fe-Per } \pm \text { Dol } \\
\text { Fe-Per } \pm \text { Fe-Al-Si-phase } \\
\text { Ca-pvsk+Ca-Mg-pvsk+Cpx } \\
\text { Majorite (former, Cpx+Gt) }\end{array}$ & $\begin{array}{l}3 \\
2 \\
1 \\
1\end{array}$ & 35 \\
\hline Total & & 20 & 100 \\
\hline
\end{tabular}

The most common inclusion (in 6 diamonds) is a FeAl-Si mineral, possibly $\left(\mathrm{AlSiO}_{3}\right) \mathrm{OH}$ - phase egg of Lower Mantle (LM) derivation.
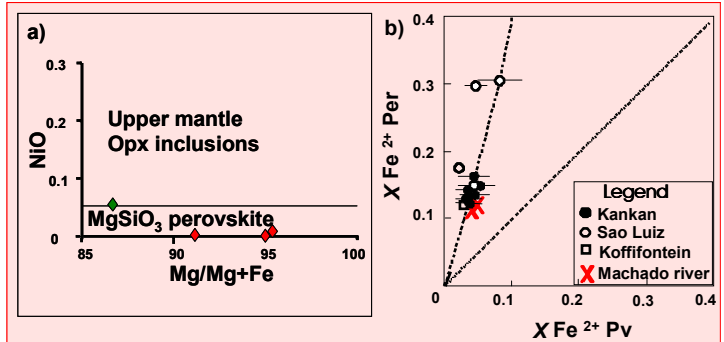

Fig. 6. Chemistry of Machado $\mathrm{MgSiO}_{3}$ inclusions:

a) $\mathrm{NiO}$ content; b) $\mathrm{Fe}^{2+}-\mathrm{Mg}$ partitioning between coexisting MgSi-perovskite - periclase inclusions.

The former MgSi-perovskites are characterised by less than $0.03 \mathrm{wt} . \% \mathrm{NiO}$ and by similarity to results of experimental $\mathrm{Mg}$-Fe partitioning between $\mathrm{MgSiO}_{3}$ and coexisting ferropericlase as shown on the Fig 6.

The high $\mathrm{Mg}$ periclase has $\mathrm{Mg \#} 88$ and is identical to those from Kankan diamond inclusions (Fig. 7). The coexisting in Machado diamonds MgSi-perovskite has Mg\# 95 in agreement with high PT experimental results suggesting origin in LM (Brey et al, 2004)

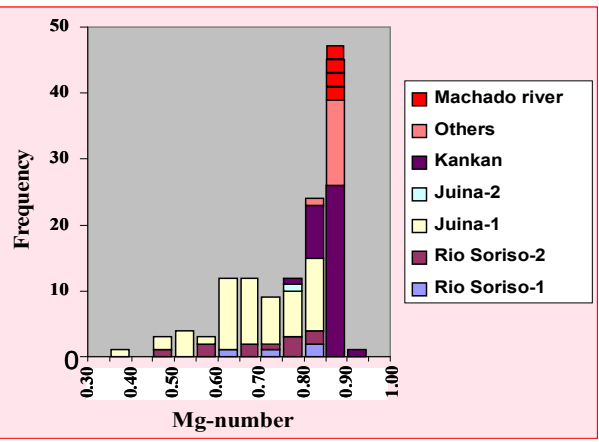

Fig. 7. Machado Fe-periclase diamond inclusions Mg\# compared with world-wide data. 
The trace element concentration in the MgSiperovskite is not high, as found elsewhere. Machado River CaSi-perovskite has contents of $\mathrm{Sr}, \mathrm{Zr}$ and HREE similar to world-wide CaSi-perovskites which are enriched in incompatible TE, especially REE.

The sole majoritic garnet was reconstructed from bulk composition of a 2-phase $\mathrm{Cpx}+\mathrm{Gt}$ inclusion, interpreted as exsolution because of their unconventional chemistry. According to $\mathrm{Si}$ excess in the former majorite it originated at $15 \mathrm{GPa}$ pressure within the transition zone (TZ).

Eclogitic paragenesis. Machado E diamonds do not contain pyrope-almandine garnet or omphacite. Most common are low-Ni sulphides and $\mathrm{SiO}_{2}$ inclusions. Rare clinopyroxene is high in $\mathrm{Mg}$ and $\mathrm{Ca}$ and has low jadeite content.

Peridotitic paragenesis. $\mathrm{P}$ stones contain inclusions of olivine, enstatite and Ni-rich sulphides. The olivines have Mg\# 90-94 and high Ni content (0.35 - 0.38 wt. $\%$ giving evidence about origin in conventional depleted mantle. However, such characteristic minerals as chromite and garnet found world-wide in $\mathrm{P}$ diamonds have not been seen in Machado River stones.

\section{Carbon isotope composition}

Machado diamonds show distinctive $\mathrm{C}$-isotope values corresponding to their three genetic groups. UD diamonds were formed from heavy carbon isotopes identical to the carbonate signatures $\delta^{13} \mathrm{C}=-1$ to $-3 \%$. $\mathrm{P}$ stones have normal mantle composition of $\delta^{13} \mathrm{C}=-4$ to $-6 \%$. E crystals show wide composition range from (i) heavy mantle values of $\delta^{13} \mathrm{C}=-3 \%$, to (ii) a light $\mathrm{C}$ isotope group characteristic of subducted carbon $\left(\delta^{13} \mathrm{C}=-12 \%\right.$ ), and even to (iii) an extremely light value group $\left(\delta^{13} \mathrm{C}=-18 \%\right)$, suggestive of organic matter source.

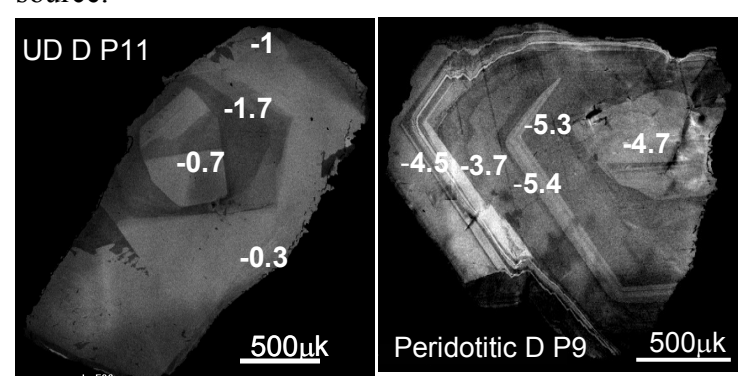

Fig. 8. $\delta^{13} \mathrm{C} \%$ of UD and $\mathrm{P}$ stones in core-rim traverses, shown on the CL diamond images.

Many diamonds are almost homogeneous in $\delta^{13} \mathrm{C}$ (Fig. 8). In few cases of heterogeneity for $\mathrm{E}$ crystals, $\mathrm{N}$ content and aggregation have negative correlation with $\delta^{13} \mathrm{C}$. A rough variation in $\mathrm{C}$ isotopes recorded in one $\mathrm{UD}$ and one $\mathrm{E}$ diamond of group (iii) gives evidence of a sharp change of isotope source during their growth, possibly caused by a vertical movement of the diamond forming system within the mantle (subduction or uplifting).

\section{Discussion and conclusions}

Machado River population consists of 35\% UD, 40\% E and $25 \% \mathrm{P}$ diamonds. Carolina and Pimento Bueno pipes are possible sources of the diamonds without abrasion $(30 \%)$. The abraded and irradiated stones $(70 \%)$ were likely transported from paleo-collectors.

$\mathrm{P}$ and $\mathrm{E}$ diamonds were formed at three depth levels in the lithospheric upper mantle within the $1000-1200^{\circ} \mathrm{C}$ temperature range obtained from their $\mathrm{N}$ content and aggregation. The most unusual result is the presence of UD sub-lithospheric diamonds in the alluvials. These diamonds have the typical characteristics of UD stones such as stress features, deformation, and breakages, lack of internal zonation and predominance of $\mathrm{N}$-free type II diamond. The mineral inclusion association of $\mathrm{Fe}-\mathrm{Per}$, former $\mathrm{MgSi}-$ and $\mathrm{Ca}-\mathrm{Si}$ perovskites and possible $\mathrm{Fe}-\mathrm{Al}$-Si-phase agrees with their formation in the upper part of LM. Sulphides and micro-inclusions of carbonates most likely represent a fluid/melt component from the diamond forming environment.

Subducted carbonates with a small proportion of organic matter were the main source of carbon for the Machado LM diamond formation. Our data agrees with the suggestion that the diamond protolith for LM diamonds was former oceanic crust that accumulated at the top of the LM (Ringwood, 1991). Both Machado and Juina UD diamond occurrences lie on the " $125 \mathrm{deg}$ lineament" of Crough et al. (1980). This lineament is associated with a belt of alkaline volcanics occurrences linked to plume activity as the continent moved over the Trindade hot spot. Such an upwelling could be a link between ultradeep diamonds and kimberlite generation.

\section{References}

Brey, G.P., Bulatov, V., Girnis, A., Harris, J.W., Stachel, T. Ferropericlase - a lower mantle phase in the upper mantle. 2004. 8th International Kimberlite Conference selected papers, vol.2, 647-663.

Crough, S.T., Morgan, W.J. and Hargraves, R.B., 1980. Kimberlites: their relation to mantle hotspots. Earth and Planetary Science Letters, Vol. 50, Issue 1, p. 260-274.

McCammon, C.A., Stachel, T., Harris, J.W., 2004. Iron oxidation state in lower mantle mineral assemblages II. Inclusions in diamonds Kankan, Guinea. Earth and Planetary Science Letters, 222, 423-424.

Ringwood A.E., 1991. Phase transformations and their bearing on the constitution and dynamics of the mantle. Geochimica et Cosmochimica Acta, 55, 2083-2110.

Stachel, T., Brey. G.P., Harris, J.W., 2005. Inclusions in sublithospheric diamonds: glimpses of the deep Earth. Elements, Vol.1, No.2, 73-78.

Taran, M.N., Kvasnytsya, V.M., Langer, K, Lichenko K.O. 2006. Infrared spectroscopy study of nitrogen centers in microdiamonds from Ukrainian Neogene placers. European Journal of Mineralogy, 18, 71-81

Teixeira, N.A., Belther, J., Lucas, H., Gaspar, J.C. \& Brasil, F.X., 2001. Geotectonic setting and mantle composition along AZ 125 lineament - Brazil. Abstracts, 3rd Brazilian Symposium on Diamond Geology and 1st South American Symposium on Diamond Geology, Brasilia, p. 21. 